\title{
Posh accent and vocal attractiveness in British English
}

\author{
Li Jiao ${ }^{1}$, Chengxia Wang ${ }^{2}$, Cristiane $\mathrm{Hsu}^{2}$, Peter Birkholz ${ }^{3}$, Yi Xu ${ }^{2}$ \\ ${ }^{1}$ School of Foreign Languages, Tongji University, China \\ ${ }^{2}$ Dept of Speech, Hearing and Phonetic Sciences, University College London, UK \\ ${ }^{3}$ Inst of Acoustics and Speech Communication, Technische Universität Dresden, \\ Germany \\ https://doi.org/10.36505/ExLing-2017/08/0012/000314
}

\begin{abstract}
Posh accent in British English is associated with upper class. Previous research on poshness has been centred on vocabulary, grammar and phonology, but little is known about the phonetic properties. This study, as part of a larger project, is an attempt to connect posh accent with attractiveness of voice through a common set of dimensions originating from emotional prosody research. Using VocalTractLab and Praat, we created stimuli varying in voice quality, nasality, formant shift ratio, pitch shift and duration. Results of two separate perception experiments showed that only voice quality and formant shift ratio functioned significantly. Breathy voice sounded the most posh and attractive, and pressed voice the least. Likewise, utterances with the smallest formant shift ratio sounded the most posh and attractive.
\end{abstract}

Key words: poshness, attractiveness, voice quality, formant shift ratio

\section{Introduction}

Poshness, or posh accent, is a British notion that a person sounds upper class when speaking. Previous studies on poshness have centred on vocabulary, phonology and grammar (Ross 1954, 1970, Fox 2004). One is heard as posh if s/he speaks clearly and uses correct grammar and certain words. However, there have also been anecdotal claims about phonetic properties associated with a posh accent that have not yet been systematically studied.

One language coach suggests that speaking further forward in the mouth and holding tight the lips make a person sound posh (YouTube 2015). Another suggests speaking as slowly as possible (YouTube 2013). Yet a third claims that posh people hold back their emotions in public (YouTube 2014), which implies that they also sound cold and detached. Finally, there are also claims that link nasality to posh accent (Herbert 1988, Buuren 1988).

In this study, which is part of a larger project (Jiao et al. in press), we explore these ideas with a method developed for studying affective prosody and vocal attractiveness ( $\mathrm{Xu}$ et al. 2013). The method is based on the hypothesis that emotions and attractiveness are both vocally encoded with acoustic parameter that project a large or small body size to dominate or appease the listener (Ohala 1984).

ExLing 2017: Proceedings of 8th Tutorial and Research Workshop on Experimental Linguistics, 19-22 June, Heraklion, Crete, Greece 


\section{Method}

\section{Stimuli}

A short statement You are feeling mellow, read by a 16-year-old Cambridgeaccented male speaker from the Intonational Variation in English (IViE) corpus (Grabe et al. 1998), was used as a template for articulatory synthesis using VocalTractLab (Birkholz 2013). Six base sentences were created that varied in voice quality (breathy, modal and pressed) and nasality (-nasality and +nasality). In the next step, these six base sentences were modified with the PSOLA algorithm implemented in Praat (Boersma 2001) to generate a total of 162 stimuli that differed as follows:

Formant shift ratios ranging from compressed to expanded spectrum (0.9, $1.0,1.1)$, stimulating a lengthened or shortened vocal tract.

Pitch shifts ranging from lowered to raised $(-3,0,3)$ median pitch of the utterance in semitones.

Duration ratios ranging from shortened to lengthened $(0.8,1.0,1.2)$ total duration of the utterance.

\section{Participants}

Seventeen native English speakers (average age: 24.2; 8 females), who selfreported to be able to tell a posh accent, took part in the experiments in a lab at the Department of Speech, Hearing and Phonetic Sciences, UCL and a quiet study room in Scape Shoreditch, London.

\section{Perception tasks}

Two experiments were run in which subjects judged how posh (experiment 1) and how attractive (experiment 2) each utterance sounded on a 5-point scale. There were 324 trials in each experiment as all stimuli were heard twice in random order. Each utterance was heard only once in each trial.

\section{Results}

Repeated Measures ANOVAs showed main effects of voice quality and formant shift ratio for both poshness [voice quality $(\mathrm{F}(2,32)=7.848, p=$ $0.0017)$; formant shift ratio $(\mathrm{F}(2,32)=6.356, p=0.0047)]$ and attractiveness [voice quality $(\mathrm{F}(2,32)=21.899, p<0.0001)$; formant shift ratio $(\mathrm{F}(2,32)=9.896, p=0.0005)]$. Student-Newman-Keuls tests showed that breathy voice received significantly the highest scores for both poshness and attractiveness. For the other voice qualities, pressed was rated lower than modal in both tasks although the difference in poshness was rather small. Likewise, utterances with the largest formant shift ratio (1.1) sounded the least posh and attractive. Although there was no significant difference 
between the smaller ratio (0.9) and the original (1.0), their average scores showed a favour for the longer vocal tract (0.9) in both tasks. There were also marginal four-way interactions among voice quality, nasality, formant shift ratio and duration for both poshness $(\mathrm{F}(8,128)=2.056, p=0.0449)$ and attractiveness $(\mathrm{F}(8,128)=2.566, p=0.0125)$, which are too complex and subtle to interpret.

Apart from the above, there was also a marginal interaction between voice quality and nasality $(\mathrm{F}(2,32)=3.642, p=0.0376)$ for poshness. For attractiveness, there was a main effect of duration $(\mathrm{F}(2,32)=3.67, p=$ $0.0367)$, whereby the shorter durations ( 0.8 and 1.0$)$ had significantly higher scores, and the 0.8 ratio had the highest mean score. Additionally, for attractiveness, there were two-way interactions between nasality and pitch shift $(\mathrm{F}(2,32)=5.646, p=0.0079)$, formant shift ratio and pitch shift $(\mathrm{F}(4$, $64)=11.73, p<0.0001)$ and formant shift ratio and duration $(\mathrm{F}(4,64)=$ 2.964, $p=0.0261$ ) as can be seen in Figure 1. Due to lack of space, however, these two-way interactions can not be further discussed.
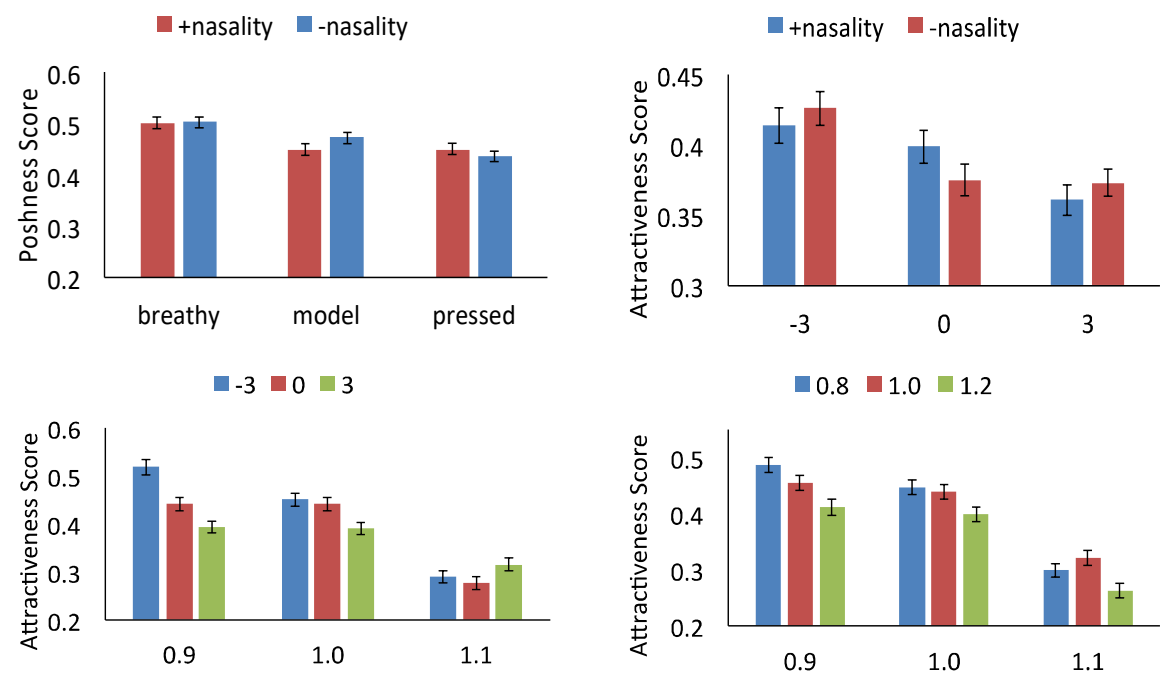

Figure 1. Upper left: Normalized poshness scores as a function of voice quality \& nasality; Rest of the plots: Normalized attractiveness scores as a function of nasality \& pitch shift (upper right), formant shift ration \& pitch shift (lower left) and formant shift ratio \& duration (lower right).

\section{Discussion and conclusion}

The results of the two experiments are partially consistent with the impressionistic accounts of posh accent in terms of social connotations (but not phonetic properties). That is, with a lengthened vocal tract that projects a 
large body size, it sounds dominant and authoritative, qualities that happen to be also associated with an attractive male voice (Xu et al. 2013). On the other hand, both poshness and attractiveness are associated with a breathy voice, which was found in attractive male as well as female voices (Xu et al. 2013). Posh accent is therefore kind of like an attractive male voice, masculine but not aggressive. Contrary to the anecdotes, nasality has no main effects on either poshness or attractiveness, although it is involved in some interactions, which can be further explored in future studies.

\section{Acknowledgements}

Thank Mia and Judy whose posh English play inspired this project.

\section{References}

Birkholz P. 2013. Modeling consonant-vowel coarticulation for articulatory speech synthesis. PLoS ONE, 8(4), e60603.

Boersma, P. 2001. Praat, a system for doing phonetics by computer. Glot International 5, 341-345.

Buuren, L. Van 1988. Margaret Thatcher's pronunciation: an exercise in ear-training. Journal of the international phonetic association 18 (01), 26-38.

Fox, K. 2004. Watching the English. London: Hodder and Stoughton Ltd.

Grabe, E., Nolan, F. and Farrar, K. 1998. IViE - a Comparative transcription system for intonational variation in English. In Mannell, R. and Robert-Ribes, J. (ed.), Proceedings of 5th International Conference on Spoken Language Processing, 1259-1262, Sydney, Australia.

Herbert, J. 1988. Broadcast speech and the effect of voice quality on the listener: a study of the various components which categorise listener perception by vocal characteristics. $\mathrm{PhD}$ thesis, University of Sheffield.

Jiao, L., Wang, C., Hsu, C., Birkholz, P. and Xu, Y. in press. Does posh English sound attractive? in Proceedings of INTERSPEECH 2017, Stockholm, Sweden.

Ohala, J. 1984. An ethological perspective on common cross-language utilization of $\mathrm{F}_{0}$ of Voice. Phonetica 41,1-16.

Ross, A. 1954. Linguistic class-indicators in present-day English. Neuphilologische Mitteilungen 55 (1), 20-56.

Ross, A. 1970. How to pronounce it. London: Hamilton.

Xu, Y., Lee, A., Wu, W., Liu, X. and Birkholz, P. 2013. Human vocal attractiveness as signaled by body size projection. PloS ONE, 8 (4), e62397.

YouTube. 2013. How to Speak POSH English. [online] Available at: https://www.youtube.com/watch?v=BLyPhCR4S1M. [Accessed 19 May 2017].

YouTube. 2014. Why Posh People are Cold. [online] Available at: https://www.youtube.com/watch?v=rKAGTKAwgqE. [Accessed 19 May 2017].

YouTube. 2015. How to sound posh - Part one. [online] Available at: https://www.youtube.com/watch?v=Nj0Rh_1kDw [Accessed 19 May 2017]. 